\title{
$\alpha$-TEA inhibits the growth and motility of human colon cancer cells via targeting RhoA/ROCK signaling
}

\author{
JIALIN YAO $^{1}$, PENG GAO ${ }^{2}$, YANG XU ${ }^{3}$ and ZHAOZHU LI $^{1}$ \\ ${ }^{1}$ Department of Pediatric Surgery, The Second Affiliated Hospital of Harbin Medical University, Harbin, \\ Heilongjiang 150081; ${ }^{2}$ Department of Pediatric Surgery, The Harbin Children's Hospital; ${ }^{3}$ Department of Oncology, \\ The Third Affiliated Hospital of Harbin Medical University, Harbin, Heilongjiang 150001, P.R. China
}

Received July 4, 2015; Accepted May 3, 2016

DOI: $10.3892 / \mathrm{mmr} .2016 .5525$

\begin{abstract}
Colon or colorectal cancer is a common type of human cancer, which originates in the intestine crassum or the rectum. In the United States, colorectal cancer has one of the highest rates of cancer-related mortality. Investigating novel chemotherapeutic approaches is significant in the treatment of cancers, such as colorectal cancer. $\alpha$-tocopherol ether-linked acetic acid ( $\alpha$-TEA) is a potent anticancer agent in multiple types of human cancer. However, its effect remains to be determined in colon cancer. In this study, HCT116 and SW480 human colon cancer cells were used to investigate the anticancer role of $\alpha$-TEA. It was demonstrated that $\alpha$-TEA inhibited cell proliferation, migration and invasion in colon cancer cells. Furthermore, it was shown that $\alpha$-TEA downregulated the activity of RhoA and phosphorylated Rho-associated protein kinase (ROCK) substrate myosin light chain (MLC) using a pull-down assay and western blotting, respectively, implying that the RhoA/ROCK pathway is involved in $\alpha$-TEA-mediated cell growth and motility inhibition. In order to confirm this hypothesis a RhoA inhibitor (clostridium botulinum $\mathrm{C} 3$ exoenzyme), a ROCK inhibitor (Y27632) and RhoA small interfering (si)RNA were applied to block RhoA/ROCK signaling. This resulted in the attenuation of MLC phosphorylation, and augmentation of $\alpha$-TEA-mediated growth and motility inhibition in colon cancer cells. In conclusion, these results indicate that $\alpha$-TEA inhibits growth and motility in colon cancer cells possibly by targeting RhoA/ROCK signaling. Moreover, combined with RhoA or ROCK inhibitors, $\alpha$-TEA may exhibit a more effective inhibitory role in colon cancer.
\end{abstract}

Correspondence to: Dr Zhaozhu Li, Department of Pediatric Surgery, The Second Affiliated Hospital of Harbin Medical University, 246 Xuefu Road, Harbin, Heilongjiang 150081, P.R. China

E-mail: lizhzhu88@163.com

Key words: colon cancer, $\alpha$-tocopherol ether-linked acetic acid, proliferation, motility, RhoA, Rho-associated protein kinase, myosin light chain

\section{Introduction}

Colon (or colorectal) cancer is a common type of malignant tumor, which is characterized by abnormal cell proliferation without control in the lining of the colon and rectum. It is the third most common type of cancer in Western countries. Approximately 136,830 cases of colorectal cancer were diagnosed, and $\sim 50,310$ patients succumbed to colorectal cancer in the United States in 2014 (1). The incidence, diagnostics and therapeutic options have also changed in the last decades in China. In the past ten years, the incidence rate has doubled and it reached $\sim 13 \%$ in 2015. In addition, clinical studies indicated that when screened for the disease, African Americans tend to be diagnosed with colorectal cancer at a younger age than Caucasians (2). When colon cancer is diagnosed in the early stages, it is curable and colon resection is an appropriate treatment for non-muscle invasive colon cancer. However, surgery is not curative when cancer cells have invaded into the muscle, and the prognosis for patients with colon cancer at a more advanced stage remains poor. Therefore, chemotherapy is an alternative treatment strategy. Exhibiting a selective cytotoxicity to tumor cells, use of $\alpha$-tocopherol ether-linked acetic acid ( $\alpha$-TEA) has as a chemotherapeutic agent has been a focus of in vivo and in vitro studies in multiple types of cancer (3-8). However, the exact impact and the mechanism underlying its effect remains to be established.

Rho family members of GTPases have been reported to be important in the regulation of certain biological functions associated with cell movement and actin cytoskeleton rearrangement (9). RhoA, as a member of GTPase family, is involved in cell-cycle progression, gene transcription, cell polarity and focal adhesion complex assembly (10). Similar to other GTPases, RhoA can be changed from active to inactive states by the exchange between GTP-bound and GDP-bound states. RhoA and its downstream effectors, such as Rho-associated protein kinase (ROCK) and myosin light chain (MLC), are closely associated with multiple cellular biological functions such as cytoskeleton reorganization, smooth muscle contraction, cell motility, proliferation and protein expression (11-16). Rho-kinase modulates cell stress fiber formation and intercellular connections to influence metastasis, proliferation or anchorage-independent growth of tumor cells (17-26). Considering that high level expression of $\mathrm{RhoA}$ is detected in a number of malignant tumors, the regulation 
of RhoA activity has been applied to cancer control due to its participation in cancer-associated signaling pathways (27-30). The protein expression of RhoA is markedly higher in prostate cancer cells than in normal prostate cells, as increased RhoA protein expression is associated with abnormal cell growth (27). RhoA silencing decreased androgen-regulated prostate cancer cell survival and motility (27). RhoA has also been shown to be activated in gastric cancer cells; additionally, downregulation of RhoA activity prevented the abnormal proliferation of gastric cancer cells by targeting RhoA-mammalian Diaphanous 1 signaling (28). Furthermore, RhoA expression has been found to be markedly increased in testicular tumor tissue compared with that in normal tissue; protein expression of RhoA and ROCK were also higher in advanced cancer stages compared with that in early stage cancer $(31,32)$.

The present study investigated the impact of $\alpha$-TEA on the proliferation and motility of colon cancer cells, and determined whether the RhoA/ROCK signaling pathway is involved in mechanism underlying the effect of $\alpha$-TEA.

\section{Materials and methods}

Cell culture. HCT116 human colon carcinoma and SW480 human colon adenocarcinoma cells (American Type Culture Collection; Manassas, VA, USA) were grown in high glucose Dulbecco's modified Eagle's medium (DMEM; Gibco, Thermo Fisher Scientific, Inc., Waltham, MA, USA) supplemented with $10 \%$ fetal bovine serum (FBS; Lonza, Levallois-Perret, France) and added to $100 \mu \mathrm{g} / \mathrm{ml}$ penicillin/streptomycin. Cell lines were cultured at $37^{\circ} \mathrm{C}$ in a $5 \% \mathrm{CO}_{2}$ incubator.

Proliferation assay. Cell proliferation was assessed by MTT dye conversion. Briefly, $10^{4}$ cells were seeded in a $96-$ well flat bottom plate after transfection. Cells were cultured in a $37^{\circ} \mathrm{C}, 5 \% \mathrm{CO}_{2}$ incubator for $24 \mathrm{~h}$, followed by another $4 \mathrm{~h}$ after $20 \mu \mathrm{l}$ MTT $(5 \mathrm{mg} / \mathrm{ml})$ was added to each well. Then, $200 \mu \mathrm{l}$ dimethylsulfoxide (DMSO) was added to the washed well to lyse cells. Absorbance was detected using an enzyme-linked immunosorbent assay spectrophotometer at $490 \mathrm{~nm}$.

Migration and invasion assay. Cell migration was assessed by a Transwell assay using $6.5 \mathrm{~mm}$ chambers with $8-\mu \mathrm{m}$ pore membranes. Then, $600 \mu 1$ DMEM medium with or without $\alpha$-TEA, which was synthesized using a combination of previously described methods was added to the lower chamber $(33,34)$. The suspension of $5 \times 10^{4}$ cells in $100 \mu \mathrm{l}$ DMEM medium with $1 \%$ fetal calf serum (Sigma-Aldrich, St. Louis, MO, USA) was plated into the upper chamber with or without $\alpha$-TEA. After $20 \mathrm{~h}$, cells on the undersurface of the polycarbonate membranes were stained with crystal violet (Amresco LLC, Cleveland, OH, USA) for $10 \mathrm{~min}$ at room temperature and six randomly selected fields were observed with a BX50 light microscope (Olympus, Tokyo, Japan) at $\mathrm{x} 100$ magnification. The same procedure was conducted for the invasion assay, except that $70 \mu \mathrm{l}$ of $1 \mathrm{mg} / \mathrm{ml}$ Matrigel (BD Biosciences) was added into the upper surface of the membrane and the incubation time was prolonged to $24 \mathrm{~h}$.

Transfection of HCT116 and SW480 cells by anti-RhoA small interfering (si)RNA. A small RNA that does not match any known genes was used as an siRNA control (Ambion, Austin, TX, USA). Cells $\left(2 \times 10^{6}\right)$ were then transfected with RhoA or control siRNAs (Ambion) using Lipofectamine-2000 (Invitrogen; Thermo Fisher Scientific, Inc.) in 100-mm diameter cell culture dishes. At $24 \mathrm{~h}$ after transfection, the cells were cultured in $100 \mathrm{~mm}$ dishes and grown for $24 \mathrm{~h}$ prior to treatment with $10 \mu \mathrm{M} \alpha$-TEA.

Reverse transcription-quantitative polymerase chain reaction. RNA was extracted using the Total RNA Isolation kit (A\&A Biotechnology, Gdynia, Poland) according to the manufacturer's instructions. Total RNA generated cDNA by reverse transcription PCR using the RevertAid First Strand cDNA synthesis kit (Fermentas International, Vilnius, Lithuania). The cDNA was amplified using TaqMan Gene Expression Assay (Applied Biosystems, Foster City, CA, USA) in the system containing specific primers for RhoA and glyceraldehyde 3-phosphate dehydrogenase (GAPDH), and FAM-labeled fluorescent probes. The following primers and probes were used: Forward: 5'-AATGACGAGCACACGAGACGGGA-3', reverse: 5'-ATGTACCCAAAAGCGCCAATCCT-3'. and TaqMan fluorogenic probe: 5'-CCCACCCTCTCCGGTGTGTCTGTCGGTT-3' for RhoA; and forward: 5'-CGACTTCAACAGCAACTCCCACTCTTCC-3', reverse: 5'-TGGGTGGTCCAGGGTTTCTTACTCCTT-3' and fluorogenic probe: 5'-ATGCCCTCCCCCATGCCATCCTGCGT-3' for the GAPDH gene. The genes were amplified by a first step of $120 \mathrm{sec}$ at $95^{\circ} \mathrm{C}$, followed by 45 cycles of $30 \mathrm{sec}$ at $95^{\circ} \mathrm{C}$, $30 \mathrm{sec}$ at $60^{\circ} \mathrm{C}$, and $30 \mathrm{sec}$ at $72^{\circ} \mathrm{C}$. The real-time fluorescence detection was performed with the ABI PRISM 7700 Sequence Detector (Applied Biosystem, Thermo Fisher Scientific, Inc.). The quantity of mRNA expression for RhoA was calculated using the formula $2^{-\Delta \Delta C q}$ and was normalized to the level of GAPDH (35). The relative quantity of mRNA in siRNAtreated cells was presented as the relative value of mRNA in the untreated cells.

RhoA activity assays. The activity of RhoA was assessed in colon cancer cells by a pull-down assay for GTP-bound RhoA (36). GTP-bound RhoA was precipitated from cell lysates with Rhotekin RBD (Upstate Biotechnology, Lake Placid, NY, USA). Active RhoA and total RhoA were detected by western blotting using an anti-RhoA mAb.

MLC phosphorylation. Cells were starved for $24 \mathrm{~h}$ in serum-free DMEM medium, and then were treated with or without $\alpha$-TEA for $1 \mathrm{~h}$ in $5 \% \mathrm{CO}_{2}$ at $37^{\circ} \mathrm{C}$. The cells were lysed with cell lysis buffer B (1\% Triton X-100, $30 \mathrm{mM}$ HEPES NaOH, pH 7.4; 1 mM EGTA, $20 \mathrm{mM} \mathrm{NaF,} 1 \mathrm{mM}$ $\mathrm{Na}_{3} \mathrm{VO}_{4}, 40 \mathrm{mM} \mathrm{Na} \mathrm{P}_{2} \mathrm{O}_{7}, 100 \mathrm{mM} \mathrm{NaCl}, 10 \mu \mathrm{g} / \mathrm{ml}$ aprotinin, $10 \mu \mathrm{g} / \mathrm{ml}$ leupeptin, $10 \mu \mathrm{g} / \mathrm{ml}$ pepstatin and $1 \mathrm{mM}$ PMSF). The supernatants from the centrifuged $(10,000 \mathrm{x} g$ for $10 \mathrm{~min})$ cell lysates were collected and then were assayed by western blotting using anti-MLC or anti-pMLC antibodies.

Western blotting. Cells were washed with phosphate-buffered saline and lysed in lysis buffer (50 mM HEPES pH 8.0; 1\% Triton X-100, $1.5 \mathrm{mM}$ EDTA, $150 \mathrm{mM} \mathrm{NaCl}, 1 \mathrm{mM} \mathrm{Na} \mathrm{VO}_{4}$, $50 \mathrm{mM} \mathrm{NaF}, 1 \mathrm{mM} \mathrm{MgCl}$, $20 \mathrm{mM} \beta$-glycerophosphate, $10 \%$ glycerol, $1 \mu \mathrm{M}$ pepstatin $\mathrm{A}, 1 \mathrm{mM}$ phenylmethylsulphonyl 
A

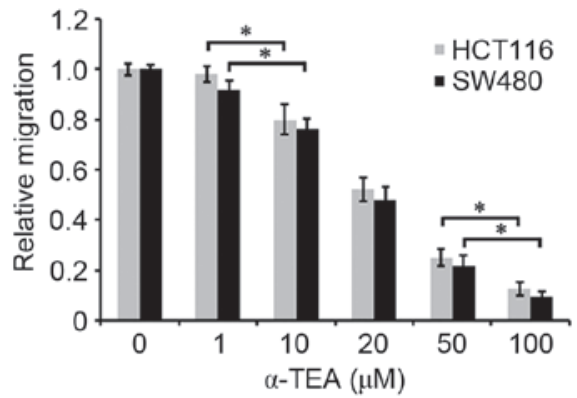

B

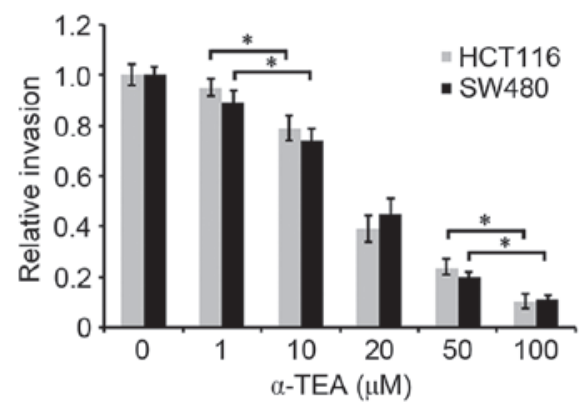

C

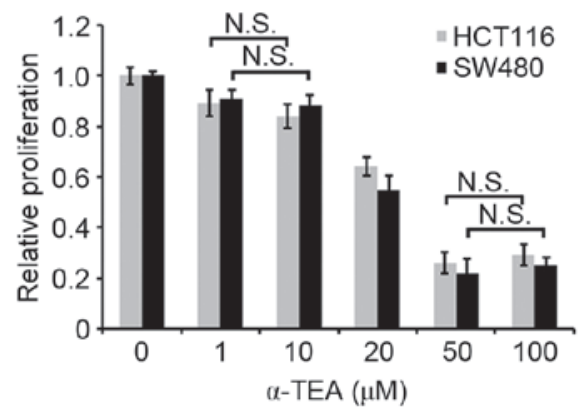

Figure 1. $\alpha$-TEA attenuated migration and invasion of colon cancer cells. (A) Migration and (B) invasion of HCT116 and SW480 cells measured by a Transwell assay. Cells were seeded into the upper chamber in the absence or presence of $\alpha$-TEA. Following incubation, the migrating and invading cells were stained and counted. (C) Proliferation of cells was assessed by an MTT assay. Migration, invasion or proliferation ability was expressed as a ratio relative to non-treated control. Data are presented as the mean \pm standard error of the mean of three independent experiments. " $\mathrm{P}<0.05$. N.S., not significant; $\alpha$-TEA, $\alpha$-tocopherol ether-linked acetic acid.

fluoride and $10 \mu \mathrm{g} / \mathrm{ml}$ aprotonin). Cell lysate was centrifuged at $10,000 \mathrm{x} \mathrm{g}$ for $10 \mathrm{~min}$, and the supernatant was collected. Protein samples were quantified using a bicinchoninic acid assay Protein Assay kit (Beyotime, Beyotime Institute of Biotechnology, Jiangsu, China). Total protein samples (50 $\mu \mathrm{g})$ were separated by $12 \%$ sodium dodecyl sulfate-polyacrylamide gel electrophoresis and transferred to polyvinylidene fluoride membranes (EMD Millipore, Beverly, MA, USA). Rabbit anti-RhoA (1:1,000, cat. no. sc-179) and mouse anti-GAPDH antibodies (1:5,000, cat. no. sc-365062) (Santa Cruz Biotechnology Inc., Santa Cruz, CA, USA), rabbit antiMLC (1:1,000, cat. no. \#3672), rabbit anti-phosphorylated MLC (pMLC; 1:1,000, cat. no. 3674S) antibodies, and horseradish peroxidase (HRP)-conjugated goat anti-rabbit IgG secondary antibody (1:2,000, cat. no. \#7074) (Cell Signaling Technology, Beverly, MA, USA) and HRP conjugated horse anti-mouse $\operatorname{IgG}$ secondary antibody (1:2,000, cat. no. \#7076, Cell Signaling Technology) were used. Enhanced chemiluminescence-detecting reagent (Amersham Biosciences, Buckinghamshire, UK) was used for development. The protein
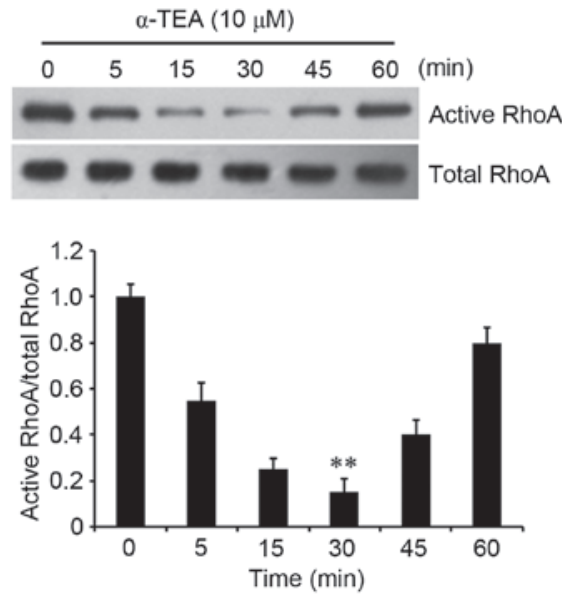

Figure 2. RhoA activation was inhibited by $\alpha$-TEA. (A) HCT116 cells were cultured in serum-free Dulbecco's modified Eagle's medium for $24 \mathrm{~h}$, and then exposed to $\alpha$-TEA. Following treatment with $\alpha$-TEA, the cells were harvested. RhoA activity was assessed by a rhotekin-based pull-down assay over time following treatment with $10 \mu \mathrm{M} \alpha$-TEA. Active RhoA (in pull-down samples) and total RhoA (in total lysates) were detected by western blotting using an anti-RhoA antibody. The blots were quantified by densitometry, and the results were expressed as ratio relative to the values obtained in non-treated control cells $(0 \mathrm{~min}) .{ }^{* *} \mathrm{P}<0.01$ vs. control. $\alpha$-TEA, $\alpha$-tocopherol ether-linked acetic acid.
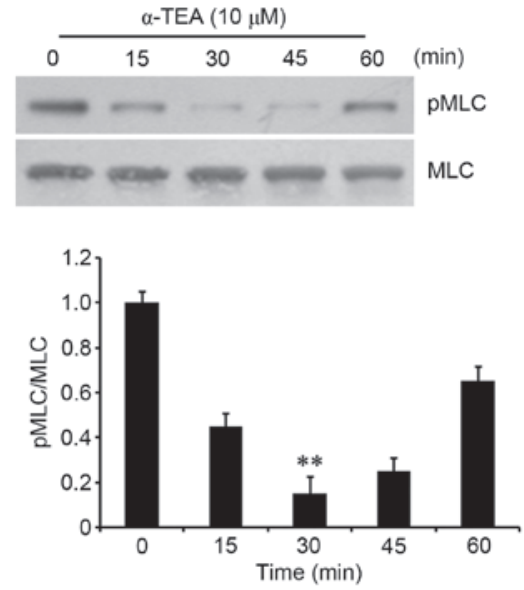

Figure 3. $\alpha$-TEA reduced MLC phosphorylation. HCT116 cells were starved in serum-free Dulbecco's modified Eagle's medium for $24 \mathrm{~h}$, and then treated with $10 \mu \mathrm{M} \alpha$-TEA and monitored over time. MLC phosphorylation was evaluated by western blotting. The blots were quantified by densitometry, and the results were expressed as a ratio relative to the values obtained in non-treated control cells $(0 \mathrm{~min}) .{ }^{* *} \mathrm{P}<0.01$ vs. control. $\alpha$-TEA, $\alpha$-tocopherol ether-linked acetic acid; MLC, myosin light chain; pMLC, phosphorylated MLC.

blots were quantified by densitometry using Quantity One software v 4.5.0 (Bio-Rad Laboratories Inc., Hercules, CA, USA), and the amounts were expressed relative to the internal reference GAPDH.

Statistical analysis. SPSS version 11.0 (SPSS Inc., Chicago, IL, USA) was used to analyze the experimental data. Data are presented as the mean \pm standard error of the mean. All of the experiments were repeated in at least three times. $\mathrm{P}<0.05$ was considered to indicate a statistically significant difference. 
A

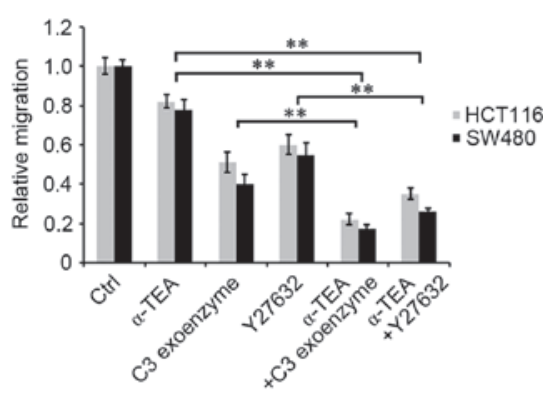

B

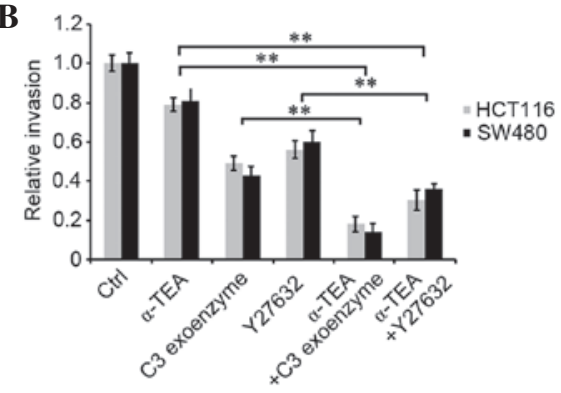

C Ctrl $\alpha$-TEA C3 $\alpha$-TEA+C3 Ctrl $\alpha-T E A$ Y27632 $\alpha$-TEA+Y27632
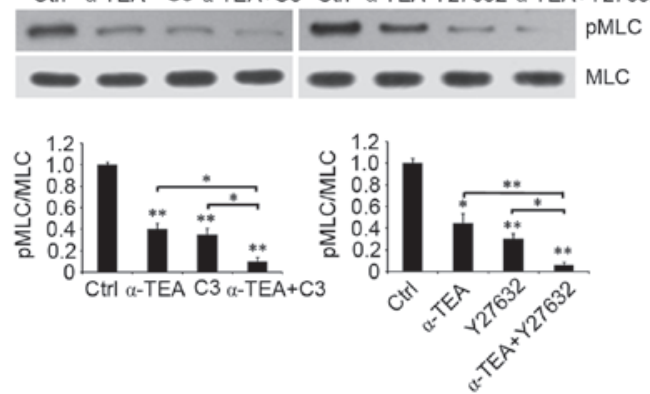

D

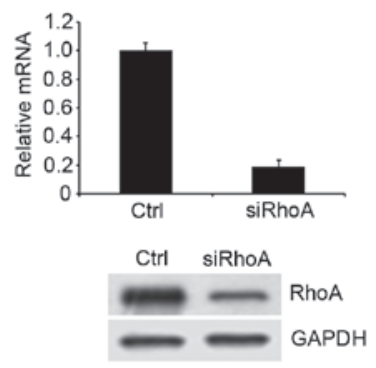

$\mathbf{E}$

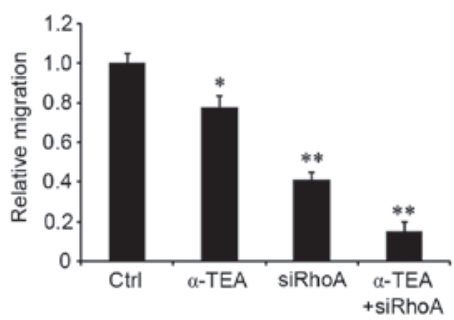

$\mathbf{F}$

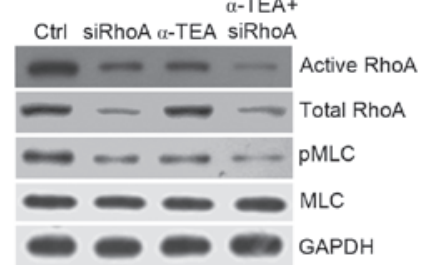

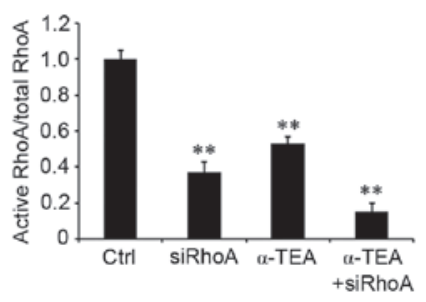

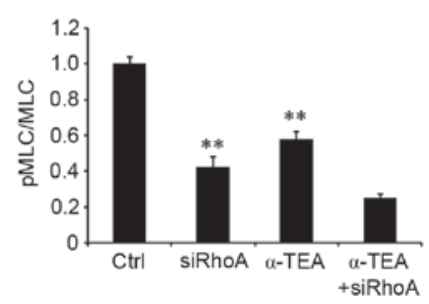

Figure 4. Effects of RhoA and ROCK inhibitors and RhoA siRNA combined with $\alpha$-TEA on the migration and invasion of colon cancer cells. Untreated control and $10 \mu \mathrm{M} \alpha$-TEA-treated HCT116 and SW480 cells were induced with or without $50 \mu \mathrm{g} / \mathrm{ml}$ RhoA inhibitor C3 exoenzyme or $50 \mu \mathrm{M}$ ROCK inhibitor Y27632. (A) Migration and (B) invasion were detected using a Transwell assay. (C) Impact of inhibitors of RhoA and ROCK combined with $\alpha$-TEA on MLC phosphorylation in HCT116 cells. Untreated control and $\alpha$-TEA-treated cells were induced with or without inhibitors of RhoA and ROCK. MLC phosphorylation was evaluated by western blotting using anti-MLC and anti-pMLC antibodies. The blots were quantified by densitometry, and the results are expressed as a ratio relative to the values obtained in untreated control cells. Data are presented as the mean \pm standard error of the mean of three independent experiments. ${ }^{*} \mathrm{P}<0.05$ and ${ }^{* *} \mathrm{P}<0.01$. (D) Impact of RhoA siRNA on RhoA mRNA and protein expression. HCT116 cells were transfected with RhoA siRNA for $48 \mathrm{~h}$. mRNA and protein were extracted, and then reverse transcription-polymerase chain reaction and western blotting were used to detect RhoA mRNA and protein expression, respectively. (E) HCT116 cells were transfected with or without RhoA siRNA for $48 \mathrm{~h}$, and then treated with $10 \mu \mathrm{M} \alpha$-TEA and cell migration was evaluated by Transwell assay. ${ }^{*} \mathrm{P}<0.05$ and ${ }^{* *} \mathrm{P}<0.01$ vs. control. (F) Activity of RhoA and MLC phosphorylation were assessed by western blotting using anti-RhoA, anti-pMLC and anti-MLC antibodies. The blots were quantified by densitometry. ${ }^{* *} \mathrm{P}<0.01$ vs. control. MLC, myosin light chain; pMLC, phosphorylated MLC; GAPDH, glyceraldehyde 3-phosphate dehydrogenase; siRNA, small interfering RNA; $\alpha$-TEA, $\alpha$-tocopherol ether-linked acetic acid; ROCK, Rho-associated protein kinase.

\section{Results}

$\alpha$-TEA attenuates the migration and invasion of colon cancer cells. To investigate whether $\alpha$-TEA affects the motility of colon cancer cells, migration and invasion assays were conducted in vitro. As shown in Fig. $1 \mathrm{~A}$ and B, $\alpha$-TEA attenuated cellular migration and invasion in HCT116 and SW480 cells in a dose-dependent manner between $1 \mu \mathrm{M}$ and
$100 \mu \mathrm{M}$. Cell proliferation was assessed by an MTT assay to determine whether it was regulated by $\alpha$-TEA at various concentrations for 24 h. $\alpha$-TEA decreased the cell proliferation at 20,50 or $100 \mu \mathrm{M}$ for $24 \mathrm{~h}$, and $\alpha$-TEA mediated the most significant decrease of cell proliferation at $50 \mu \mathrm{M}$ concentration compared with non-treated control group. (Fig. 1C). Cell proliferation was not indicated to be significantly different between 1 and $10 \mu \mathrm{M} \alpha$-TEA treatment (Fig. 1C). These data 
A

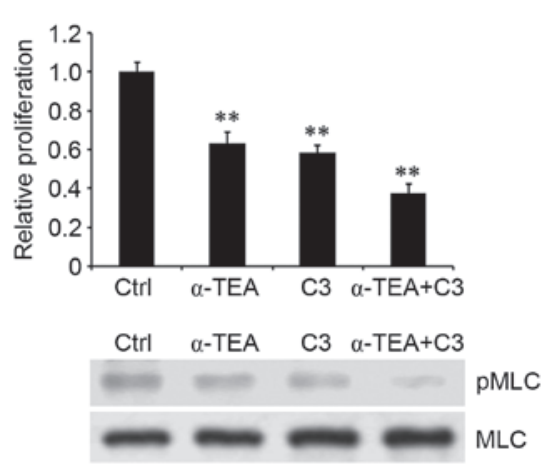

B

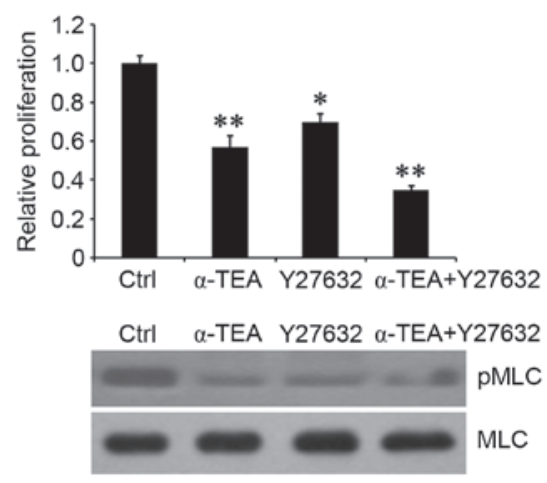

Figure 5. Effect of treatment with RhoA and ROCK inhibitors in combination with $\alpha$-TEA on proliferation. HCT116 cells was treated with $20 \mu \mathrm{M}$ $\alpha$-TEA, (A) plus RhoA inhibitor C3 exoenzyme, or (B) plus ROCK inhibitor Y27632 for $24 \mathrm{~h}$. Cell proliferation was assessed by an MTT assay. MLC phosphorylation was evaluated by western blotting. The blots were quantified by densitometry. ${ }^{*} \mathrm{P}<0.05$ and ${ }^{* *} \mathrm{P}<0.01$ vs. control. ROCK, Rho-associated protein kinase; $\alpha$-TEA, $\alpha$-tocopherol ether-linked acetic acid; Ctrl, control MLC, myosin light chain; pMLC, phosphorylated MLC.

demonstrated that $\alpha$-TEA inhibited cell migration and invasion independently of its role in cell proliferation.

$\alpha$-TEA decreases RhoA activity. It was then investigated how $\alpha$-TEA attenuates cell proliferation and motility. RhoA, as a Rho GTPase, participates in the regulation of cell viability and cell-cycle progression. To determine whether $\alpha$-TEA affects the activity of RhoA in colon cancer cells, GTP-bound RhoA was detected in HCT116 colon cancer cells by a pull-down assay. The results demonstrated that the activity of RhoA was decreased by $10 \mu \mathrm{M} \alpha$-TEA treatment, and the activity reached the trough at $30 \mathrm{~min}$ followed by a gradual increase close to the initial level (Fig. 2). These results indicated that $\alpha$-TEA inhibited RhoA activity in HCT116 colon cancer cells.

a-TEA downregulates MLC phosphorylation. As RhoA can activate ROCK and then contribute to the phosphorylation of MLC (14), its phosphorylation in $\alpha$-TEA-treated cells was determined. Western blotting showed that the phosphorylation of MLC decreased transiently in cells treated with $10 \mu \mathrm{M}$ $\alpha$-TEA, reaching a trough at $30 \mathrm{~min}$, and then followed by a gradual increase (Fig. 3 ). These results indicated that $\alpha$-TEA decreased MLC phosphorylation.

RhoA and ROCK inhibitors, and RhoA siRNA augment $\alpha$-TEA-induced inhibition of motility. To verify the participation of members of the RhoA/ROCK signaling pathway in $\alpha$-TEAinduced inhibition of motility, HCT116 and SW480 cells were treated with $10 \mu \mathrm{M} \alpha$-TEA, plus $50 \mu \mathrm{g} / \mathrm{ml}$ RhoA inhibitor C3 exoenzyme and $50 \mu \mathrm{M}$ ROCK inhibitor Y27632 for $24 \mathrm{~h}$. Treatment with $\alpha$-TEA or inhibitors alone led to limited decrease in cell migration and invasion, whereas $\alpha$-TEA combined with each inhibitors markedly augmented inhibition of migration and invasion relative to single treatments (Fig. $4 \mathrm{~A}$ and B). $\alpha$-TEA and inhibitors of RhoA and ROCK reduced the levels of MLC phosphorylation. Combination treatment with RhoA or ROCK inhibitors enhanced $\alpha$-TEA inhibition of MLC phosphorylation (Fig. 4C), suggesting that RhoA and ROCK mediated $\alpha$-TEA-induced downregulation of MLC phosphorylation. In addition, RhoA siRNA significantly decreased RhoA mRNA and protein expression (Fig. 4D). Combination of $\alpha$-TEA and RhoA siRNA acted synergistically to inhibit cell migration (Fig. 4E), and reduced active RhoA and MLC phosphorylation in HCT116 cells (Fig. 4F). These data indicated that $\alpha$-TEA could downregulate active RhoA and MLC phosphorylation, and that $\alpha$-TEA acted synergistically with RhoA and ROCK chemical inhibitors to inhibit colon cancer cell motility.

RhoA and ROCK inhibitors enhance $\alpha$-TEA-induced proliferation inhibition. To investigate whether the RhoA/ROCK pathway is associated with $\alpha$-TEA-induced cell proliferation inhibition, HCT116 cells were treated with $20 \mu \mathrm{M} \alpha$-TEA, plus $50 \mu \mathrm{g} / \mathrm{ml}$ C3 exoenzyme or $50 \mu \mathrm{M}$ Y2 27632 for $24 \mathrm{~h}$. Treatment with $\alpha$-TEA or an inhibitor alone resulted in a significant decrease in proliferation. However, $\alpha$-TEA in combination with each inhibitor significantly enhanced inhibition of proliferation compared with the single treatments (Fig. 5A and B). Moreover, RhoA and ROCK inhibitors acted synergistically to augment $\alpha$-TEA inhibition of MLC phosphorylation, respectively (Fig. 5A and B). These results indicated that RhoA/ROCK signaling was involved in $\alpha$-TEA-mediated cell growth inhibition.

\section{Discussion}

Despite several treatment options, colon cancer remains a leading cause cancer-related mortality. A major reason for the poor prognosis of metastatic tumors is the development of drug resistance. Thus, the development of novel antitumor agents to prevent and treat colon cancer is required. $\alpha$-TEA, a vitamin $\mathrm{E}$ analogue, has chemopreventive and chemotherapeutic activities. In recent years, it has been established that $\alpha$-TEA has the ability to inhibit tumor progression in vivo $(37,38)$. The antitumor activities of $\alpha$-TEA have been extensively characterized using in vitro systems. $\alpha$-TEA has been reported to be widely used in cancer treatment based on multiple antitumor mechanisms in a variety of human cancers. $\alpha$-TEA augments the inhibition of trastuzumab on breast cancer with HER2/neu expression (39). $\alpha$-TEA inhibits tumor growth by stimulating the anticancer immune response in breast cancer (33). $\alpha$-TEA induces apoptosis via an increase in pro-death factors and decrease in pro-survival factors in human prostate cancer cells (8), and via the JNK-p73-NOXA signaling pathway in human breast cancer cells (40). $\alpha$-TEA activates Fas signaling and inhibits AKT and ERK activity, which induces the apoptosis of cisplatin-sensitive and -resistant human ovarian 
cancer cells (76). $\alpha$-TEA has been reported to exhibit antitumor and antimetastatic activities in cell culture and animal studies $(6,41)$. However, it is unclear whether $\alpha$-TEA exhibits these effects on colon cancer, and there are few studies regarding the mechanism underlying the antimetastasis associated molecular mechanism of $\alpha$-TEA. In the present study, it was demonstrated that $\alpha$-TEA inhibited proliferation and motility of colon cancer cells and researched the underlying mechanism of action.

RhoA expression is high in liver (42), skin (43) and colon (44) cancer. An increase in RhoA expression is observed in conjunction with elevated RhoA activity, poor prognosis and increased frequency of recurrence of cancer. Furthermore, increased RhoA levels were reported in ovarian (31), bladder (45), gastric (46), breast (47) and testicular (32) cancer. These data demonstrate that RhoA is closely associated with cancer progression. Metastasis is a key reason for cancer-related mortality, and is the final step in the progression of a number of solid tumors. Migration and invasion properties of tumor cells show cellular metastatic ability. In order to improve the status of cancer patients, consideration of malignant properties is required. MLC phosphorylation induces actomyosin contraction, which is closely associated with cellular migration and invasion $(41,48,49)$. In addition, RhoA can activate ROCK and stimulate the phosphorylation of MLC (14). Therefore, it is assumed that the inhibition of cellular migration and invasion mediated by $\alpha$-TEA may result from abnormal phosphorylation of MLC via RhoA/ROCK signaling. As expected, $\alpha$-TEA reduced RhoA activity and downregulated MLC phosphorylation. Moreover, the effect of $\alpha$-TEA was enhanced by co-treatment with RhoA and MLC inhibitors. However, RhoA regulates cellular biological functions in cancer through several signaling mechanisms. p27 is a RhoA binding protein, which is critical for modulating the growth and proliferation of cells. p27 regulates the cell cycle and is crucial in cell migration and motility. Binding of p27 and RhoA is involved in the regulation of the activation of the RhoA/ROCK pathway (50). In this study, p27 may participate in $\alpha$-TEA-induced inhibition of proliferation and motility of colon cancer cells via the RhoA/ROCK pathway. Additionally, p27RF-RhoA and membrane type-1 matrix metalloproteinase (MT1-MMP) are critical in tumor cell invasion. p27RF-Rho stimulates RhoA activation and promotes the formation of punctate actin structures termed invadopodia, which are important for regulating tumor cell invasion. RhoA induces invadopodia with localized concentrations of matrix protease activity that colocalize with MT1-MMP, actin and cortactin in invasive tumor cells (51). p90 ribosomal S6 kinase is an effector of the Ras-MAPK cascade and it inhibits RhoA-induced cell motility by disturbing actomyosin stability. Therefore, whether other signaling pathways or proteins are involved in the activity of $\alpha$-TEA on colon cancer cell malignance remains to be established.

In conclusion, $\alpha$-TEA downregulates RhoA/ROCK signaling and inhibits cancer progression. Thus, $\alpha$-TEA combined with RhoA/ROCK/MLC signaling pathway inhibitors may be a beneficial therapeutic strategy for preventing the development of colon cancer.

\section{Acknowledgements}

The authors would like to thank Summus Biological Technology Co., Ltd. (Harbin, China) for their technical support.

\section{References}

1. American Cancer Society, Cancer Facts \& Figures 2014. In: American Cancer Society, Atlanta, 2014.

2. Colon cancer. Healthy women. http://www.healthywomen.org/ condition/colon-cancer. Accessed July 8, 2016.

3. Anderson K, Lawson KA, Simmons-Menchaca M, Sun L, Sanders BG and Kline K: Alpha-TEA plus cisplatin reduces human cisplatin-resistant ovarian cancer cell tumor burden and metastasis. Exp Biol Med (Maywood) 229: 1169-1176, 2004.

4. Lawson KA, Anderson K, Simmons-Menchaca M, Atkinson J, Sun L, Sanders BG and Kline K: Comparison of vitamin E derivatives $\alpha$-TEA and VES in reduction of mouse mammary tumor burden and metastasis. Exp Biol Med (Maywood) 229: 954-963, 2004.

5. Shun MC, Yu W, Gapor A, Parsons R, Atkinson J, Sanders BG and Kline K: Pro-apoptotic mechanisms of action of a novel vitamin $\mathrm{E}$ analog (alpha-TEA) and a naturally occurring form of vitamin $\mathrm{E}$ (delta-tocotrienol) in MDA-MB-435 human breast cancer cells. Nutr Cancer 48: 95-105, 2004.

6. Hahn T, Szabo L, Gold M, Ramanathapuram L, Hurley LH and Akporiaye ET: Dietary administration of the proapoptotic vitamin $\mathrm{E}$ analogue alpha-tocopheryloxyacetic acid inhibits metastatic murine breast cancer. Cancer Res 66: 9374-9378, 2006.

7. Yu W, Shun MC, Anderson K, Chen H, Sanders BG and Kline K: alpha-TEA inhibits survival and enhances death pathways in cisplatin sensitive and resistant human ovarian cancer cells. Apoptosis 11: 1813-1823, 2006.

8. Jia L, Yu W, Wang P, Sanders BG and Kline K: In vivo and in vitro studies of anticancer actions of alpha-TEA for human prostate cancer cells. Prostate 68: 849-860, 2008.

9. Sanz-Moreno V, Gaggioli C, Yeo M, Albrengues J, Wallberg F, Viros A, Hooper S, Mitter R, Féral CC, Cook M, et al: ROCK and JAK1 signaling cooperate to control actomyosin contractility in tumor cells and stroma. Cancer Cell 20: 229-245, 2011.

10. Basile JR, Gavard J and Gutkind JS: Plexin-B1 utilizes RhoA and Rho kinase to promote the integrin-dependent activation of Akt and ERK and endothelial cell motility. J Biol Chem 282: 34888-34895, 2007.

11. Samuel MS, Lopez JI, McGhee EJ, Croft DR, Strachan D, Timpson P, Munro J, Schröder E, Zhou J, Brunton VG, et al: Actomyosin-mediated cellular tension drives increased tissue stiffness and $\beta$-catenin activation to induce epidermal hyperplasia and tumor growth. Cancer Cell 19: 776-791, 2011.

12. Rösel D, Brábek J, Tolde O, Mierke CT, Zitterbart DP, Raupach C, Bicanová K, Kollmannsberger P, Panková D, Vesely P, et al: Up-regulation of Rho/ROCK signaling in sarcoma cells drives invasion and increased generation of protrusive forces. Mol Cancer Res 6: 1410-1420, 2008.

13. Gadea G, de Toledo M, Anguille C and Roux P: Loss of p53 promotes RhoA-ROCK-dependent cell migration and invasion in 3D matrices. J Cell Biol 178: 23-30, 2007.

14. Amano M, Ito M, Kimura K, Fukata Y, Chihara K, Nakano T, Matsuura Y and Kaibuchi K: Phosphorylation and activation of myosin by Rho-associated kinase (Rho-kinase). J Biol Chem 271: 20246-20249, 1996.

15. Riento K and Ridley AJ: Rocks: Multifunctional kinases in cell behaviour. Nat Rev Mol Cell Biol 4: 446-456, 2003.

16. Kolodney MS and Elson EL: Contraction due to microtubule disruption is associated with increased phosphorylation of myosin regulatory light chain. Proc Natl Acad Sci USA 92: 10252-10256, 1995.

17. Somlyo AV, Bradshaw D, Ramos S, Murphy C, Myers CE and Somlyo AP: Rho-kinase inhibitor retards migration and in vivo dissemination of human prostate cancer cells. Biochem Biophys Res Commun 269: 652-659, 2000.

18. Kamai T, Tsujii T, Arai K, Takagi K, Asami H, Ito Y and Oshima H: Significant association of Rho/ROCK pathway with invasion and metastasis of bladder cancer. Clin Cancer Res 9: 2632-2641, 2003. 
19. Nakajima M, Katayama K, Tamechika I, Hayashi K, Amano Y, Uehata M, Goto N and Kondo T: WF-536 inhibits metastatic invasion by enhancing the host cell barrier and inhibiting tumour cell motility. Clin Exp Pharmacol Physiol 30: 457-463, 2003.

20. Nakajima M, Hayashi K, Egi Y, Katayama K, Amano Y, Uehata M, Ohtsuki M, Fujii A, Oshita K, Kataoka H, et al: Effect of Wf-536, a novel ROCK inhibitor, against metastasis of B16 melanoma. Cancer Chemother Pharmacol 52: 319-324, 2003.

21. Xue F, Takahara T, Yata Y, Xia Q, Nonome K, Shinno E, Kanayama M, Takahara S and Sugiyama T: Blockade of Rho/ Rho-associated coiled coil-forming kinase signaling can prevent progression of hepatocellular carcinoma in matrix metalloproteinase-dependent manner. Hepatol Res 38: 810-817, 2008.

22. Wong CC, Wong CM, Tung EK, Man K and Ng IO: Rho-kinase 2 is frequently overexpressed in hepatocellular carcinoma and involved in tumor invasion. Hepatology 49: 1583-1594, 2009.

23. Sahai E, Ishizaki T, Narumiya S and Treisman R: Transformation mediated by RhoA requires activity of ROCK kinases. Curr Biol 9: 136-145, 1999.

24. Ying H, Biroc SL, Li WW, Alicke B, Xuan JA, Pagila R, Ohashi Y, Okada T, Kamata Y and Dinter H: The Rho kinase inhibitor fasudil inhibits tumor progression in human and rat tumor models. Mol Cancer Ther 5: 2158-2164, 2006

25. Zhang S, Tang Q, Xu F, Xue Y, Zhen Z, Deng Y, Liu M, Chen J, Liu S, Qiu M, et al: RhoA regulates G1-S progression of gastric cancer cells by modulation of multiple INK4 family tumor suppressors. Mol Cancer Res 7: 570-580, 2009.

26. Zohrabian VM, Forzani B, Chau Z, Murali R and JhanwarUniyal M: Rho/ROCK and MAPK signaling pathways are involved in glioblastoma cell migration and proliferation. Anticancer Res 29: 119-123, 2009.

27. Schmidt LJ, Duncan K, Yadav N, Regan KM, Verone AR, Lohse CM, Pop EA, Attwood K, Wilding G, Mohler JL, et al: RhoA as a mediator of clinically relevant androgen action in prostate cancer cells. Mol Endocrinol 26: 716-735, 2012.

28. Zhang S, Tang Q, Xu F, Xue Y, Zhen Z, Deng Y, Liu M, Chen J, Liu S, Qiu M, et al: RhoA regulates G1-S progression of gastric cancer cells by modulation of multiple INK4 family tumor suppressors. Mol Cancer Res 7: 570-580, 2009.

29. Doublier S, Riganti C, Voena C, Costamagna C, Aldieri E, Pescarmona G, Ghigo D and Bosia A: RhoA silencing reverts the resistance to doxorubicin in human colon cancer cells. Molecular Cancer Research 6: 1607-1620, 2008.

30. Molli PR, Pradhan MB, Advani SH and Naik NR: RhoA: A therapeutic target for chronic myeloid leukemia. Molecular cancer 11: 16, 2012 .

31. Horiuchi A, Imai T, Wang C, Ohira S, Feng Y, Nikaido T and Konishi I: Up-regulation of small GTPases, RhoA and RhoC, is associated with tumor progression in ovarian carcinoma. Lab Invest 83: 861-870, 2003

32. Kamai T, Yamanishi T, Shirataki H, Takagi K, Asami H, Ito Y and Yoshida K: Overexpression of RhoA, Rac1 and CDC42 GTPases is associated with progression in testicular cancer. Clin Cancer Res 10: 4799-4805, 2004.

33. Hahn T, Jagadish B, Mash EA, Garrison K and Akporiaye ET: $\alpha$-Tocopheryloxyacetic acid: A novel chemotherapeutic that stimulates the antitumor immune response. Breast Cancer Res 13: R4, 2011

34. Lawson KA1, Anderson K, Menchaca M, Atkinson J, Sun L, Knight V, Gilbert BE, Conti C, Sanders BG and Kline K: Novel vitamin E analogue decreases syngeneic mouse mammary tumor burden and reduces lung metastasis. Mol Cancer Ther 2:437-444, 2003.
35. Livak KJ and Schmittgen TD: Analysis of relative gene expression data using real-time quantitative PCR and the 2(-Delta Delta C(T)) Method. Methods 25: 402-408, 2001.

36. Yanagisawa M and Anastasiadis PZ: p120 catenin is essential for mesenchymal cadherin-mediated regulation of cell motility and invasiveness. J Cell Biol 174: 1087-1096, 2006.

37. Fariss MW, Fortuna MB, Everett CK, Smith JD, Trent DF and Djuric Z: The selective antiproliferative effects of alphatocopheryl hemisuccinate and cholesteryl hemisuccinate on murine leukemia cells result from the action of the intact compounds. Cancer Res 54: 3346-3351, 1994.

38. Malafa MP, Fokum FD, Mowlavi A, Abusief M and King M: Vitamin E inhibits melanoma growth in mice. Surgery 131: 85-91, 2002.

39. Hahn T, Bradley-Dunlop DJ, Hurley LH, Von-Hoff D, Gately S, Mary DL, Lu H, Penichet ML, Besselsen DG, Cole BB, et al: The vitamin $\mathrm{E}$ analog, alpha-tocopheryloxyacetic acid enhances the anti-tumor activity of trastuzumab against HER2/neu-expressing breast cancer. BMC Cancer 11: 471, 2011

40. Wang P, Yu W, Hu Z, Jia L, Iyer VR, Sanders BG and Kline K: Involvement of JNK/p73/NOXA in vitamin E analog-induced apoptosis of human breast cancer cells. Mol Carcinog 47: 436-445, 2008.

41. Schlienger S, Campbell S and Claing A: ARF1 regulates the Rho/MLC pathway to control EGF-dependent breast cancer cell invasion. Mol Biol Cell 25: 17-29, 2014

42. Li XR, Ji F, Ouyang J, Wu W, Qian LY and Yang KY: Overexpression of RhoA is associated with poor prognosis in hepatocellular carcinoma. Eur J Surg Oncol 32: 1130-1134, 2006.

43. Collisson EA, Carranza DC, Chen IY and Kolodney MS: Isoprenylation is necessary for the full invasive potential of RhoA overexpression in human melanoma cells. J Invest Dermatol 119: $1172-1176,2002$

44. Fritz G, Just I and Kaina B: Rho GTPases are over-expressed in human tumors. Int J Cancer 81: 682-687, 1999.

45. Kamai T, Tsujii T, Arai K, Takagi K, Asami H, Ito $\mathrm{Y}$ and Oshima H: Significant association of Rho/ROCK pathway with invasion and metastasis of bladder cancer. Clin Cancer Res 9: 2632-2641, 2003

46. Pan Y, Bi F, Liu N, Xue Y, Yao X, Zheng Y and Fan D: Expression of seven main Rho family members in gastric carcinoma. Biochem Biophys Res Commun 315: 686-691, 2004.

47. Jiang WG, Watkins G, Lane J, Cunnick GH, Douglas-Jones A, Mokbel K and Mansel RE: Prognostic value of rho GTPases and rho guanine nucleotide dissociation inhibitors in human breast cancers. Clin Cancer Res 9: 6432-6440, 2003.

48. Shin DH, Chun YS, Lee KH, Shin HW and Park JW: Arrest defective-1 controls tumor cell behavior by acetylating myosin light chain kinase. PLoS One 4: e7451, 2009.

49. Kidera Y, Tsubaki M, Yamazoe Y, Shoji K, Nakamura H, Ogaki M, Satou T, Itoh T, Isozaki M, Kaneko J, et al: Reduction of lung metastasis, cell invasion, and adhesion in mouse melanoma by statin-induced blockade of the Rho/Rho-associated coiledcoil-containing protein kinase pathway. J Exp Clin Cancer Res 29: 127, 2010.

50. Larrea MD, Wander SA and Slingerland JM: p27 as Jekyll and Hyde: Regulation of cell cycle and cell motility. Cell Cycle 8: 3455-3461, 2009.

51. Hoshino D, Tomari T, Nagano M, Koshikawa N and Seiki M: A novel protein associated with membrane-type 1 matrix metalloproteinase binds p27 (kip1) and regulates RhoA activation, actin remodeling, and matrigel invasion. J Biol Chem 284: 27315-27326, 2009. 